\title{
Simulasi Sistem Dinamik untuk Memprediksi Keberhasilan Strategi Pengembangan Laboratorium Prodi Teknik Industri di UAI
}

\author{
Nunung Nurhasanah, Yona Tantya Utama \\ Program Studi Teknik Industri, Fakultas Sains dan Teknologi \\ Universitas Al Azhar Indonesia, Jl. Sisingamangaraja, Jakarta 12110 \\ Penulis untuk Korespondensi/E-mail: nunungnurhasanah@uai.ac.id
}

Abstrak - Pada tahun pertama, penelitian ini telah menghasilkan 2 strategi untuk mengembangkan laboratorium Prodi TI. Melalui strategi pertama, yaitu penetrasi pasar, Prodi TI akan mampu menghasilkan pemasukan sendiri, tanpa tergantung dari banyaknya jumlah mahasiswa yang masuk. Pemasukan dapat diperoleh melalui Pelaksanaan Training, workshop atau in house training. Melalui strategi kedua, yaitu strategi pengembangan produk artinya Prodi TI sekaligus menerapkan budaya riset bagi dosen dan mahasiswanya. Dengan mengembangkan produk dari hasil penelitian antara dosen dan mahasiswa akan meningkatkan keterampilan mahasiswa dalam keilmuan teori dan praktis khususnya. Simulasi sistem dinamik digunakan untuk memprediksi keberhasilan strategi pengembangan Lab TI-UAI. Validasi yang digunakan untuk pengujian model ini adalah dengan statistik U-Theil's. Simulasi sistem dinamik untuk strategi penetrasi pasar memprediksi untuk 48 periode ke depan, bahwa skenario melaksanakan kegiatan praktikum untuk mahasiswa eksternal, training dosen dan karyawan akan lebih mendatangkan peningkatan pendapatan Lab TI jika saat ini dilaksanakan 1 minggu sekali pada setiap hari sabtu. Terbukti dengan U-Theil's yang lebih kecil dibanding skenario kedua, yaitu sebesar 0,556. Dengan pendapatan pada akhir periode ke-48 sebesar Rp.174.000.000. Strategi kedua, yaitu strategi pengembangan produk. Untuk saat ini hasil prediksi yang terbaik adalah terus konsisten produktif dalam menghasilkan riset, buku, HKI dan kerjasama. Hal ini dinyatakan dengan nilai U-Theil's sebesar 0,0831. Dengan pendapatan pada akhir periode ke-50 sebesar Rp.200.513.300.

Abstract - This research has produced two strategies for developing IE Department laboratory in the first year. Through the first strategy, that is the market penetration, IE department will be able to generate income by themselves, without depending on the student intake. Income can be obtained through the implementation of training, workshops or in-house training. Through the second strategy, the product development strategy, it means that IE department should implement the culture of research for both lectures and students. By developing products from the research between lectures and students, it will be able to improve student skills in scientific theory and practical. Dynamic system simulation is used to predict the success of the development strategy of the IE laboratory. U-Theil's statistic is used to validate this model. In order to predict market penetration strategy, simulation will be running for the next $\mathbf{4 8}$ periods, that scenario is to having lab activities for external students, training for lecturer and training for employee. These activities will increase IE's revenue if the lab is implemented training once a week, in Saturday. Statistic U-Theil's has proven that the first scenario is good enough because the score is 0,556 , which was smaller than the second scenario. The revenue at the end of the 48th period is IDR.174.000.000. By dynamic simulation, the first scenario from the second strategy has chosen. That is lecturers must be productive in research activities, produce books, Intelektual Property Right (IPR) and cooperation, continuously and consistently. Statistic U-Theil's value is 0.0831 , and the revenue at the end of the 50th period is IDR.200.513.300. 


\section{PENDAHULUAN}

$\mathrm{P}$ enelitian ini merupakan penelitian lanjutan dari hasil penelitian tahun pertama. Pada tahun pertama, dihasilkan dua strategi untuk mengembangkan laboratorium Prodi TI, yaitu penetrasi pasar dan pengembangan produk [1].

Melalui penetrasi pasar, Prodi TI akan mampu menghasilkan pemasukan sendiri, tanpa tergantung dari banyaknya jumlah mahasiswa yang masuk. Pemasukan dapat diperoleh melalui Pelaksanaan Training, workshop atau in house training.

Pelaksanaan training yang mungkin ditawarkan adalah: (1) Enterprise Resource Planning, (2) Penggunaan Software seperti AutoCad, Inventor, SPSS, Promodel, Power Simulation, Matlab, (3) Interpersonal skill, (4) Production planning, (5) Statistik, (6) Manajemen Operasional (7) Manajemen proyek, dan materi lain yang terkait dengan keilmuan dan kompetensi TI-UAI.

Dengan melaksanakan strategi pengembangan produk artinya Prodi TI sekaligus menerapkan budaya riset bagi dosen dan mahasiswanya. Dengan mengembangkan produk dari hasil penelitian antara dosen dan mahasiswa akan meningkatkan ketrampilan mahasiswa dalam keilmuan teori dan praktis khususnya.

Pada dasarnya perumusan strategi pengembangan Lab Prodi TI sejalan dengan misi UAI untuk meningkatkan kualitas pendidikan, penelitian dan pelayanan kepada masyarakat dengan menerapkan kaidah enterprising university. Rumusan strategi pengembangan ini juga terkait erat dengan pencitraan UAI sebagai enterprising university.

Bahwa Prodi TI siap berinovasi dalam bidang pengembangan keilmuan melalui program training atau workshop yang ditawarkan, dan bidang penelitian yang menghasilkan produk berupa buku, karya ilmiah, desain industri, model optimasi, supply chain modeling, simulation modeling, machine prototype, 3D layout, dan 3D production line, sesuai dengan kompetensi sebagai Industrial Engineering.

Berdasarkan strategi yang telah dirumuskan, maka perlu dilakukan tahapan berikutnya, yaitu memprediksi keberhasilan strategi pengembangan Lab TI yang akan diterapkan untuk kurun waktu 4 tahun mendatang. Prediksi keberhasilan strategi dilakukan menggunakan pendekatan simulasi sistem dinamis dengan bantuan perangkat lunak Power Simulation.

Penerapan strategi pengembangan Lab TI perlu diketahui tingkat keberhasilannya. Bagaimana keberhasilan penerapan strategi pengembangan Lab TI, dapat diketahui dengan melakukan prediksi melalui simulasi sistem dinamik. Keberhasilan dalam menerapkan strategi pengembangan Lab TI tentunya akan mempengaruhi penilaian standar akreditasi Prodi TI.

Dengan demikian, hal ini akan meningkatkan mutu lulusan sarjana teknik industri yang unggul dan bermartabat serta memiliki kemampuan Intelektual di bidang Sistem Manufaktur dan Manajemen Bisnis yang berlandaskan nilai-nilai spiritual, moral, dan etika Islam

\section{TINJAUAN PUSTAKA}

Laboratorium adalah sebuah ruangan baik tertutup maupun terbuka yang dirancang sesuai dengan kebutuhan untuk melakukan aktivitas yang berkaitan dengan fungsi-fungsi pendidikan, penelitian dan pengabdian kepada masyarakat.

Aktivitas yang dimaksud adalah kegiatan yang saling terintegrasi, serta ditunjang oleh adanya suatu infrastruktur yang dibutuhkan demi terwujudnya hasil optimal. Laboratorium di perguruan tinggi adalah tempat berlangsungnya kegiatan praktikum dan penelitian yang mendukung pembelajaran dan pengembangan keilmuan. [2]

Menurut Coyle dalam [3] sistem dinamik berhubungan dengan waktu yang sangat tergantung dari bagaimana perilaku mengatur sistem dengan tujuan yang menggambarkan sistem dan pemahamannya, baik dengan model kualitatif maupun kuantitatif, bagaimana informasi umpan balik mempengaruhi perilaku sistem, dan merancang struktur umpan balik informasi dan mengendalikan kebijakan melalui simulasi dan optimasi. Pemahaman terhadap rangkaian kejadian yang rumit dan berubah menurut waktu, yang terdapat di belakang pola garis hidup bergelombang adalah pemahaman dinamika dari suatu sistem. Simulasi merupakan penyelesaian atau perhitungan tahap demi tahap dari persamaan matematika yang menggambarkan keadaan sistem untuk mengetahui perubahan yang terjadi pada sistem tersebut sehingga diketahui perilakunya [4]. 
Simulasi sistem dinamik telah digunakan sebagai alat penelitian dalam kegiatan penelitian yang telah dilakukan sebelumnya untuk menentukan profit dari pengembangan model bisnis IKM Tekstil [5]

\section{METODE PENELITIAN}

Penelitian ini merupakan lanjutan dari penelitian tahun 2012, yang telah menghasilkan rumusan strategi pengembangan Lab TI. Penelitian lanjutan yang dilaksanakan tahun 2013 adalah memprediksi keberhasilan strategi pengembangan Lab TI. Diagram metodologi penelitian disajikan pada Gambar 1.

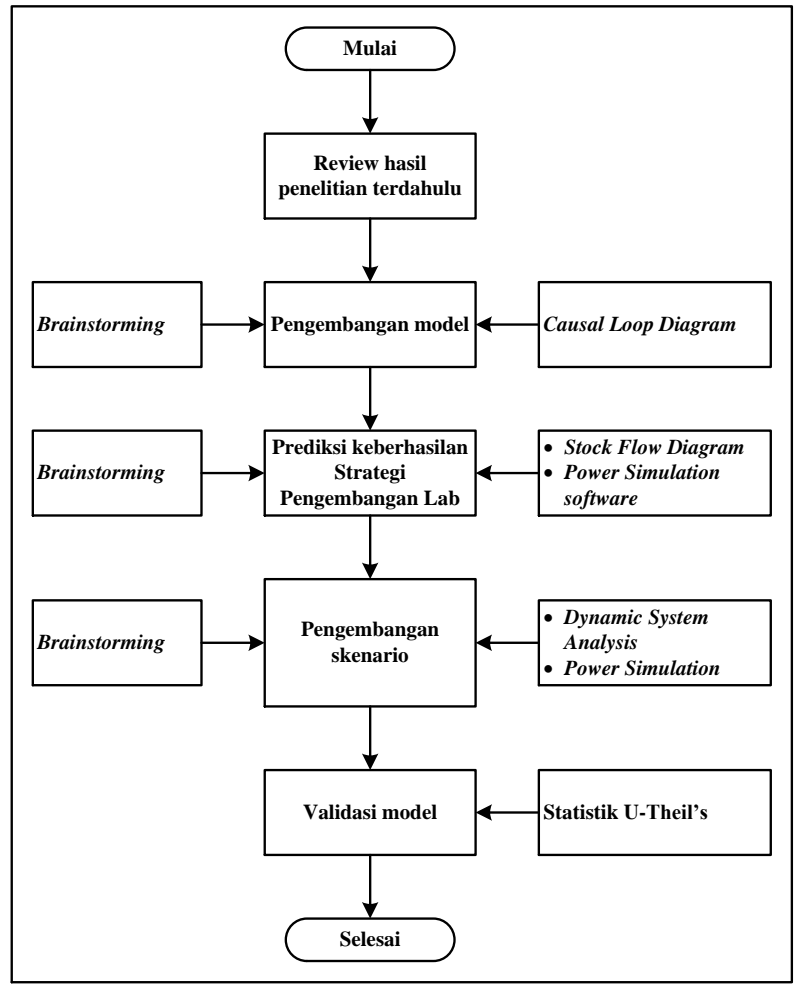

Gambar 1. Metode Penelitian

Langkah awal yang dilakukan pada penelitian tahun ini adalah mereview kembali hasil penelitian berupa rumusan strategi pengembangan Lab TI. Review dilakukan dalam bentuk diskusi melalui brainstorming dengan Tim Peneliti, Kaprodi, Laboran dan Dosen Tetap yang memanfaatkan lab untuk proses pembelajaran.

Hasil review akan dilanjutkan untuk memodelkan dua strategi yang telah dirumuskan. Model akan dikembangkan berdasarkan Causal Loop Diagram (CLD) yang dibangkitkan dengan bantuan software Power simulation (Powersim). CLD dikembangkan berdasarkan hasil brainstorming dengan stake holder, yang dalam hal ini adalah: (1) Kaprodi, (2) Dosen Tetap, (3) Laboran, (4) Mahasiswa Tugas Akhir dan (5) Biro Akademik.

Model mental CLD akan dikembangkan menjadi Stock Flow Diagram (SFD) dengan bantuan software Powersim. SFD akan menghasilkan simulasi berdasarkan skenario strategi pengembangan Lab TI untuk periode 4 tahun mendatang.

SFD yang sudang dikembangkan harus divalidasi dengan pendekatan statistik U-Theil's. Statistik UTheil's digunakan karena memiliki kriteria hasil validasi yang tidak bias. U-Theil's menyatakan jika $\mathrm{U}<1$ artinya hasil simulasi sudah baik dan model dapat mengikuti perilaku sistem nyata. U-Theil's menyatakan $U>1$, jika hasil simulasi tidak baik, dan model belum mengikuti perilaku sistem nyata.

\section{HASIL DAN PEMBAHASAN}

\section{Model Mental Sistem Prediksi Keberhasilan Strategi Pengembangan Lab}

Sistem ini terdiri dari 4 variabel, yaitu (1) Strategi pengembangan Lab TI, (2) Pencitraan Lab TI-UAI, (3) Pendapatan TI-UAI dan (4) Investasi saranaprasarana Lab TI. CLD untuk sistem ini disajikan pada Gambar 2.

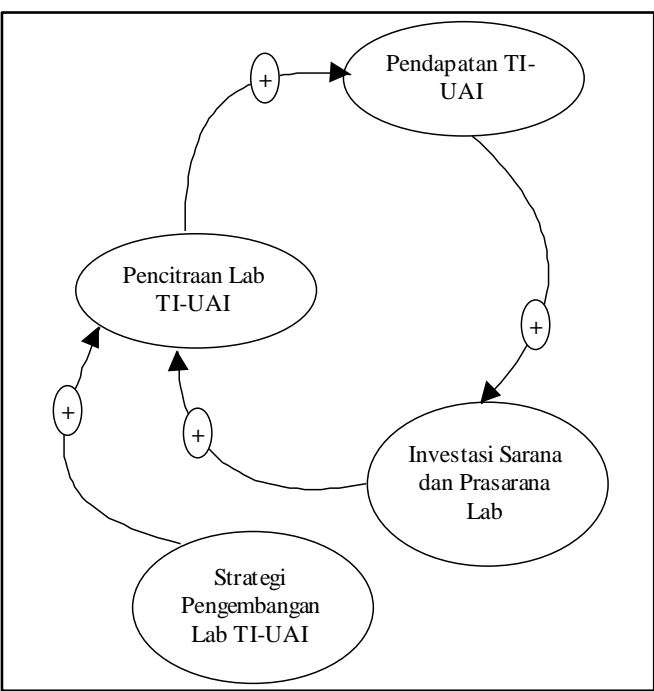

Gambar 2. CLD Prediksi Keberhasilan Pengembangan Lab TI-UAI

Variabel pertama strategi pengembangan Lab TI adalah kedua strategi yang akan diprediksi keberhasilannya jika diterapkan dalam 
Pengembangan Lab TI-UAI. Variabel kedua, yaitu pencitraan Lab TI yang terkait dengan brand Lab TI-UAI di mata Nasional dan prodi TI di universitas pesaing lainnya baik di dalam maupun luar Jabodetabek.

Variabel ketiga, yaitu pendapatan TI-UAI yang merupakan besarnya pendapatan yang dapat diperoleh prodi TI jika Lab TI dimanfaatkan secara optimal dengan kegiatan yang dapat memberikan masukan dari segi keuangan bagi prodi TI. Variabel keempat, yaitu investasi sarana dan prasarana Lab TI, yang merupakan besarnya investasi yang dapat diperoleh Lab TI dalam rangka pengembangan labnya.

Pada sistem ini dinyatakan bahwa semakin tepat dan baik strategi pengembangan lab yang dilaksanakan, maka akan semakian baik pencitraan yang terbentuk di masyarakat mengenai keberadaan Lab TI-UAI. Semakin baik pencitraan lab, maka akan mengembangkan peluang prodi TI untuk meningkatkan pendapatannya selain pemasukan dari penerimaan mahasiswa baru (PMB). Akibatnya, hal ini akan berdampak pada semakin tingginya investasi yang dapat diperoleh terhadap pengembangan sarana dan prasarana Lab TI-UAI.

\section{Sub Sistem Strategi Penetrasi Pasar}

Saat ini, berdasarkan hasil penelitian tahun pertama di 6 PTS, diketahui bahwa prodi TI belum secara kontinu dan konsisten memanfaatkan Lab nya untuk digunakan dalam kegiatan training karyawan/dosen dan praktikum mahasiswa dari luar institusi.

Sub sistem strategi penetrasi pasar merupakan salah satu strategi yang akan diprediksi keberhasilannya untuk periode 4 tahun mendatang. Strategi penetrasi pasar merupakan strategi pengembangan Lab TI yang akan dilaksanakan dengan mengoptimalkan sarana lab yang ada saat ini.

Dengan keterbatasan sarana lab yang ada saat ini akan dibuat skenario untuk memprediksi keberhasilan strategi pengembangan Lab-TI.

Skenario yang dimaksud adalah:

1. Skenario pelaksanaan kegiatan training dosen dan praktikum mahasiswa eksternal dengan jumlah mahasiswa dan ruangan kondisi saat ini, serta dilaksanakan pada hari Senin hingga Jum'at.
2. Skenario pelaksanaan kegiatan training dosen dan praktikum mahasiswa eksternal dengan peningkatan jumlah mahasiswa dan ruangan kondisi saat ini, serta dilaksanakan pada hari Sabtu hingga Minggu.

Sub sistem ini disajikan pada Gambar 3, menguraikan adanya 7 variabel. Ketujuh variabel tersebut adalah: 1. Pencitraan Lab TI; 2. Investasi sarana dan prasarana Lab; 3. Pendapatan prodi TI; 4. Biaya operasional; 5. Praktikum mahasiswa eksternal; 6. Training dosen/karyawan; dan 7. Promosi. Ketujuh variabel ini nantinya akan dituangkan dalam stock flow diagram untuk disimulasikan modelnya dan diuji validitasnya.

\section{Sub Sistem Strategi Pengembangan Produk}

Sub sistem strategi pengembangan produk merupakan strategi yang dilaksanakan untuk mengembangkan Lab TI. Bahwa produk yang akan dikembangkan merupakan hasil dari memanfaatkan Lab TI untuk dapat dijadikan luaran yang bermanfaat bagi khalayak di dunia pendidikan serta industri jasa dan manufaktur. Sub sistem ini disajikan pada Gambar 4.

Sub sistem ini memiliki 8 variabel, yaitu: 1 . Pendapatan prodi TI; 2. Pencitraan Lab TI-UAI; 3. Investasi sarana dan prasarana Lab; 4. Riset; 5. Kerjasama; 6. Hak atas kekayaan intelektual; 7. Buku; dan 8. Hibah Internal/Eksternal.

\section{Model Simulasi Sistem Prediksi Keberhasilan Strategi Pengembangan Lab TI}

Model simulasi sistem prediksi keberhasilan strategi pengembangan Lab TI akan dibangun berdasarkan Stock Flow Diagram (SFD). SFD akan dibangkitkan berdasarkan CLD yang sudah dibangun. Dua SFD yang akan dibangun adalah: 1. Sub sistem strategi penetrasi pasar; dan 2. Sub sistem strategi pengembangan produk. Kedua sub sistem strategi ini memiliki 2 skenario.

\section{Model Simulasi Sub Sistem Strategi Penetrasi Pasar}

Pengembangan sub sistem strategi ini menjadi 2 skenario, yaitu: 1. Pelaksanaan praktikum dan training pada hari Sabtu pukul 08.00-12.00; dan 2. Pelaksanaan praktikum dan training pada hari Senin hingga Jum'at di pukul 18.30-21.00. Gambar 5 menyajikan diagram SFD untuk sub sistem strategi penetrasi pasar. Sedangkan perbandingan hasil simulasi dengan perhitungan manual disajikan pada Tabel 1. 


\begin{abstract}
Skenario Pelaksanaan Praktikum di Hari Sabtu
Skenario menyatakan bahwa pelaksanaan praktikum mahasiswa eksternal dan training dosen/karyawan hanya dapat dilaksanakan pada Hari Sabtu pukul 08.00 - 12.00. Hal ini disebabkan karena terbatasnya ketersediaan ruangan di waktu kerja regular.
\end{abstract}

Ruangan yang digunakan untuk pelaksanaan praktikum mahasiswa eksternal adalah Laboratorium Perancangan Sistem Kerja dan Ergonomi, dan Laboratorium Teknik Industri yang dapat digunakan untuk praktikum yang terkait dengan software dan otomasi sistem produksi.

Laboratorium Proses Manufaktur hingga saat ini belum bisa ditawarkan untuk mahasiswa eksternal, karena waktu pelaksanaan praktikum bagi mahasiswa TI-UAI sendiri adalah di Hari Sabtu. Pelaksanaan di hari Sabtu dikerenakan daya listrik yang lebih luang dibanding hari Senin-Jum'at, dan sarana mesin proses manufaktur jumlahnya belum bervariasi, masih untuk 1 jenis mesin baru tersedia 1 mesin. Sehingga praktikum ini tidak memungkinkan untuk ditawarkan ke mahasiswa eksternal.

Pada simulasi sistem dinamik dengan bantuan SFD, dikembangkan 5 variabel utama yang akan mendukung sistem stock dan flow untuk laju pendapatan TI-UAI. Kelima variabel yang dimaksud adalah profit praktikum mahasiswa eksternal, profit training dosen, profit training karyawan, biaya promosi dan pengembangan sarana prasarana Lab TI.

Pada variabel profit praktikum mahasiswa eksternal diketahui bahwa pelaksanaan praktikum di hari sabtu secara rutin dilaksanakan tiap minggu, sehingga terdapat 4 kali praktikum dalam tiap bulan. Kecuali di bulan Ramadhan, pasca Idul Fitri dan hari raya natal untuk umat Nasrani. Hal ini diperhitungkan karena promosi dilakukan secara meluas kepada seluruh mahasiswa TI di Jabodetabek yang heterogen.

Besarnya honor trainer dalam praktikum adalah sebesar Rp.1.000.000 untuk 1 pertemuan. Biaya praktikum untuk tiap modul yang harus dikeluarkan mahasiswa eksternal adalah Rp.770.000 untuk setiap 5 mahasiswa dalam tiap batchnya. Profit yang dapat diperoleh tiap bulan untuk kegiatan praktikum adalah sebesar Rp.1.400.000. Jika ditotal untuk periode 48 bulan sesuai dengan simulasi adalah seperti yang terurai pada Tabel 1 .
Variabel profit training dosen dan karyawan memiliki sub variabel dan konstanta yang tidak berbeda jauh. Dalam kegiatan ini, honor trainer adalah Rp.2.500.000 untuk setiap modul training. Biaya training yang dapat diberikan untuk setiap dosen atau karyawan untuk setiap modul, dengan kondisi per batch sebanyak 5 orang adalah Rp.1.200.000,- Persentase profit keuntungan yang ditetapkan adalah $20 \%$, sehingga besarnya profit tiap bulan adalah Rp.4.000.000.

Kegitaan promosi berlaku untuk ketiga kegiatan ini, yaitu pencetakan leaflet, internet dan pembuatan website. Biaya pembuatan website sudah termasuk maintenance untuk tiap tahunnya. Pencetakan leaflet dilakukan setiap tahun di awal bulan sebanyak 500 eksemplar. Biaya pengiriman sudah dimasukkan dalam setiap pencetakan, karena asumsinya tidak semua leaflet dikirim. Lebih banyak akan dibawa langsung pada saat kegiatan dosen tetap mengikuti seminar atau training atau rapat koordinasi prodi TI. Total biaya promosi untuk 4 tahun adalah Rp.11.300.000.

Profit yang diperoleh tentunya untuk meningkatkan sarana dan prasarana Lab TI, oleh sebab itu dianggarkan untuk pembelian software dan upgrade PC. Software yang akan dibeli adalah Matlab, SPSS, Flexsim, Oracle dan Catia. Pembelian software akan dilaksanakan setiap tahun karena biaya yang paling murah adalah Rp.20.000.000 Sedangkan biaya upgrade PC adalah pada akhir tahun ke-48 adalah sebesar Rp.165.000.000,-. Pembelian PC dilakukan setiap 2 tahun sekali.

Hasil uji validasi menggunakan U-Theil's menghasilkan nilai $U=0,0556$. Karena nilai $U$ lebih kecil dari 1, artinya bahwa hasil simulasi sudah mendekati sistem nyata dan lebih untuk digunakan dalam memprediksi keberhasilan pengembangan Lab TI dibandingkan dengan menggunakan perhitungan manual. Berdasarkan simulasi pula, diketahui bahwa total profit yang akan diterima pada akhir periode ke-48 adalah sebesar Rp.174.000.000.

\section{Skenario Pelaksanaan Praktikum di Hari Senin- Jum'at}

Skenario menyatakan bahwa pelaksanaan praktikum mahasiswa eksternal dan training dosen/karyawan hanya dapat dilaksanakan pada Hari Senin hingga Jum'at pukul 19.00 - 21.00. Hal ini disebabkan karena terbatasnya ketersediaan ruangan di waktu kerja regular. 
Ruangan yang digunakan untuk pelaksanaan praktikum mahasiswa eksternal adalah Laboratorium Perancangan Sistem Kerja dan Ergonomi, dan Laboratorium Teknik Industri yang dapat digunakan untuk praktikum yang terkait dengan software dan otomasi sistem produksi.

Kondisi skenario kedua tidak banyak berbeda dengan skenario pertama. Pada simulasi sistem dinamik dengan bantuan SFD di sini, juga dikembangkan 5 variabel utama yang akan mendukung sistem stock dan flow untuk laju pendapatan TI-UAI. Kelima variabel yang dimaksud adalah profit praktikum mahasiswa eksternal, profit training dosen, profit training karyawan, biaya promosi dan pengembangan sarana prasarana Lab TI.

Pada variabel profit praktikum mahasiswa eksternal diketahui bahwa pelaksanaan praktikum di hari Senin hingga Jum'at secara rutin dilaksanakan tiap minggu, sehingga terdapat 2 kali praktikum setiap minggunya untuk praktikum dan training dosen/karyawan. Atau ekivalen dengan 8 kali setiap bulan untuk masing-masing kegiatan. Kecuali di bulan Ramadhan, pasca Idul Fitri dan hari raya natal.

Besarnya honor trainer dalam praktikum adalah sebesar Rp.1.500.000 untuk 1 pertemuan. Biaya praktikum untuk tiap modul yang harus dikeluarkan mahasiswa eksternal adalah Rp.1.100.000 untuk setiap 5 mahasiswa dalam tiap batchnya. Profit yang dapat diperoleh tiap bulan untuk kegiatan praktikum adalah sebesar Rp.4.000.000.

Variabel profit training dosen dan karyawan memiliki sub variabel dan konstanta yang tidak berbeda jauh. Dalam kegiatan ini, honor trainer adalah Rp.3.000.000 untuk setiap modul training. Biaya training yang dapat diberikan untuk setiap dosen atau karyawan untuk setiap modul, dengan kondisi per batch sebanyak 5 orang adalah Rp.1.560.000,- Persentase profit keuntungan yang ditetapkan adalah $20 \%$, sehingga besarnya profit tiap bulan adalah Rp.10.400.000.

Kegitaan promosi berlaku untuk ketiga kegiatan ini, yaitu pencetakan leaflet, internet dan pembuatan website. Biaya pembuatan website sudah termasuk maintenance untuk tiap tahunnya. Pencetakan leaflet dilakukan setiap tahun di awal bulan sebanyak 500 eksemplar. Biaya pengiriman sudah dimasukkan dalam setiap pencetakan, karena asumsinya tidak semua leaflet dikirim. Lebih banyak akan dibawa langsung pada saat kegiatan dosen tetap mengikuti seminar atau training atau rapat koordinasi prodi TI. Total biaya promosi untuk 4 tahun adalah Rp.11.300.000.

Profit yang diperoleh tentunya untuk meningkatkan sarana dan prasarana Lab TI, oleh sebab itu dianggarkan untuk pembelian software dan upgrade PC. Software yang akan dibeli adalah Matlab, SPSS, Flexsim, Oracle dan Catia. Pembelian software akan dilaksanakan setiap tahun karena biaya yang paling murah adalah Rp.20.000.000. Sedangkan biaya upgrade PC adalah pada akhir tahun ke-48 adalah sebesar Rp.165.000.000,-. Pembelian PC dilakukan setiap 2 tahun sekali.

Hasil uji validasi menggunakan U-Theil's menghasilkan nilai $U=0,0565$. Karena nilai $U$ lebih kecil dari 1, artinya bahwa hasil simulasi sudah mendekati sistem nyata dan lebih untuk digunakan dalam memprediksi keberhasilan pengembangan Lab TI dibandingkan dengan menggunakan perhitungan manual. Berdasarkan simulasi pula, diketahui bahwa total profit yang akan diterima pada akhir periode ke-48 adalah sebesar Rp.189.400.000.

\section{Penentuan Skenario Terbaik Strategi Penetrasi Pasar}

Berdasarkan hasil perhitungan dan simulasi sistem dinamik yang telah dilakukan, maka penentuan skenario terbaik dipilih berdasarkan nilai $U$ terkecil. Sesuai Tabel 1, maka nilai U-Theil's terkecil adalah skenario pelaksanaan praktikum dan training dosen/karyawan untuk 1 hari dalam seminggu, yaitu hanya pada hari Sabtu. Nilai U yang diperoleh adalah sebesar 0,556.

Dengan terpilihnya skenario ini, maka strategi yang digunakan dalam mengembangkan Lab TI adalah memasuki pasar baru yaitu dengan membuka atau menerima praktikum dengan peserta mahasiswa eksternal, serta menyelenggarakan training dosen/karyawan.

Pelaksanaan kegiatan tersebut untuk saat ini masih signifikan dilaksanakan pada 1 hari dalam 1 minggu, yaitu jatuh pada hari Sabtu. Hal ini mengingat keterbatasan penyediaan dan penggunaan ruang yang sudah mulai tinggi transaksi penggunaan kelasnya karena telah terjadi tren peningkatan jumlah mahasiswa. 
SFD Sub Sistem Strategi Pengembangan Produk Pengembangan sub sistem strategi ini menjadi 2 skenario, yaitu: (1) Persentase investasi sebesar 10\%, dan (2) Persentase investasi sebesar $20 \%$. Gambar 6 menyajikan diagram SFD untuk sub sistem strategi pengembangan produk. Sedangkan perbandingan hasil simulasi dengan perhitungan manual disajikan pada Tabel 2.

\section{Skenario Persentase Investasi sebesar 10\%}

Persentasi investasi merupakan variabel yang cukup signifikan jika dilakukan perubahan pada nilainya. Karena itu jika persentase investasi dimasukkan pada angka 10\%, maka laju pendapatan Prodi TI adalah sebesar Rp.200.513.500 berdasarkan hasil simulasi Powersim.

Sub sistem ini akan dijalankan hingga 50 periode. Hal ini disebabkan pengajuan HKI yang diusulkan setiap 4 tahun sekali. Sehingga diawali tahun 2014, dilanjutkan tahun 2018.

Variabel utama yang dibangkitkan di sini adalah variabel investasi yang dapat dilakukan secara mandiri. Secara mandiri artinya dengan diawali pendanaan dari intansi luar, disisihkan untuk keperluan riset mendatang, yang kalaupun tidak didanai dari pihak luar, tetap dapat melakukan riset secara mandiri.

Hal ini tidak sebatas riset, tapi juga buku, kerjasama dan HKI. Total dana yang berhasil disimulasi adalah sebesar Rp.143.000.000 hingga tahun ke-50. Invesatasi kerjasama disimulasikan hingga 5 instansi yang dapat diajak kerjasama. Pada tahun pertama disimulasikan dengan 3 mitra kerjasama, tahun kedua dengan 4 mitra, tahun ketiga dan keempat dengan 5 mitra kerjasama. Mitra yang dimaksud adalah Kementerian Kehutanan, MAK, industri makanan organic, Adora suatu industri batubara di Indonesia, dan konferensi kerjasama 6 PTS di Jakarta dan Bandung untuk penyelenggaraan seminar internasional. Investasi yang dapat diperoleh dari kerjasama adalah sebesar Rp.170.000.000.

Investasi dari kegiatan HKI hanya ditargetkan 1 judul untuk tahun pertama dan 1 judul untuk tahun kelima. Periodenya dibuat 4 tahun sekali, karena disesuaikan dengan akreditasi program studi mengenai penilaian HKI yang dapat dilakukan mengikuti periode akreditasi. Investasi dari HKI berdasarkan simulasi adalah sebesar Rp.520.000.
Nilai ini tentu tampaknya sangat kecil, karena nilai ini belum termasuk jika sertifikat paten sudah keluar dan akan dikomersialiasikan, tentunya hal ini akan mendatangkan royalty dan pemasukan tersendiri bagi prodi. Yang selanjutnya dananya dapat digunakan secara bergulir untuk persiapan kegiatan HKI di tahun berikutnya.

Dampak dengan nilai investasi tentunya agar prodi mampu mengembangkan Lab TI. Sehingga variabel pengembangan sarana dan prasarana Lab TI disimulasikan untuk pembelian software dan pengadaan PC baru setiap dua tahun sekali. Total biaya pengembangan adalah sebesar Rp.690.000.000.

Laju pendapatan berdasarkan investasi yang dilaksanakan hingga akhir period eke-50 adalah sebesar Rp.200.513.500. Berdasarkan simulasi nilai tersebut divalidasi dengan menggunakan statistic U-Theil's menghasilkan nilai sebesar 0,0831. Karena nilai U lebih kecil dari 1, maka hasil simulasi dinyatakan dapat digunakan untuk memprediksi keberhasilan pengembangan Lab TIUAI.

\section{Skenario Persentase Investasi sebesar $20 \%$}

Persentasi investasi merupakan variabel yang cukup signifikan jika dilakukan perubahan pada nilainya. Karena itu jika persentase investasi dimasukkan pada angka 20\%, maka laju pendapatan Prodi TI adalah sebesar Rp.543.527.000 berdasarkan hasil simulasi Powersim.

Variabel utama yang dibangkitkan di sini adalah variabel investasi yang dapat dilakukan secara mandiri. Total dana berdasarkan investasi dari riset yang berhasil disimulasi adalah sebesar Rp.286.000.000 hingga tahun ke-50.

Invesatasi kerjasama disimulasikan hingga 5 instansi yang dapat diajak kerjasama. Pada tahun pertama disimulasikan dengan 3 mitra kerjasama, tahun kedua dengan 4 mitra, tahun ketiga dan keempat dengan 5 mitra kerjasama. Mitra yang dimaksud adalah Kementerian Kehutanan, MAK, industri makanan organic, Adora suatu industri batubara di Indonesia, dan konferensi kerjasama 6 PTS di Jakarta dan Bandung untuk penyelenggaraan seminar internasional. Investasi yang dapat diperoleh dari kerjasama adalah sebesar Rp.340.000.000, 
Investasi dari kegiatan HKI hanya ditargetkan 1 judul untuk tahun pertama dan 1 judul untuk tahun kelima. Periodenya dibuat 4 tahun sekali, karena disesuaikan dengan akreditasi program studi mengenai penilaian HKI yang dapat dilakukan mengikuti periode akreditasi. Investasi dari HKI berdasarkan simulasi adalah sebesar Rp.1.040.000.

Nilai ini tentu tampaknya sangat kecil, karena nilai ini belum termasuk jika sertifikat paten sudah keluar dan akan dikomersialiasikan, tentunya hal ini akan mendatangkan royalty dan pemasukan tersendiri bagi prodi. Yang selanjutnya dananya dapat digunakan secara bergulir untuk persiapan kegiatan HKI di tahun berikutnya.

Dampak dengan nilai investasi tentunya agar prodi mampu mengembangkan Lab TI. Sehingga variabel pengembangan sarana dan prasarana Lab TI disimulasikan untuk pembelian software dan pengadaan PC baru setiap dua tahun sekali. Total biaya pengembangan adalah sebesar Rp.690.000.000.

Laju pendapatan berdasarkan investasi yang dilaksanakan hingga akhir period eke-50 adalah sebesar Rp.200.513.500. Berdasarkan simulasi nilai tersebut divalidasi dengan menggunakan statistik U-Theil's menghasilkan nilai sebesar 0,1429. Karena nilai U lebih kecil dari 1, maka hasil simulasi dinyatakan dapat digunakan untuk memprediksi keberhasilan pengembangan Lab TIUAI.

\section{Penentuan Skenario Terbaik Strategi Pengembangan Produk}

Produk yang dikembangkan oleh Lab TI terkait dengan peningkatan peringkat Akreditasi prodi TI. Hal ini tentunya terkait dengan Tri Darma PT, yaitu pendidikan, penelitian dan pengabdian masyarakat.

Bidang pendidikan dapat menghasilkan buku sebagai pegangan mahasiswa dalam proses KBM. Bidang penelitian merupakan bidang yang paling produktif bagi seorang dosen tetap, luaran yang dihasilkan bisa mencakup publikasi, buku, kerjasama dan HKI.

Bidang pengabdian masyarakat akan banyak menghasilkan kegiatan kerjasama. Bidang kerjasama pun dapat dihasilkan dari bidang penelitian.

Berdasarkan hasil nilai $U$ terkecil yaitu 0,0831 untuk skenario persentase investasi pengembangan produk sebesar $10 \%$. Berdasarkan hasil simulasi ini diketahui bahwa prodi TI dapat memperoleh peningkatan pendapatan pada akhir periode ke-50 sebesar Rp.200.513.500.

Berdasarkan simulasi software Powersim untuk dapat mengembangkan Lab TI-UIA, maka harus sangat digiatkan dan dimotivasi kegiatan penelitian oleh Dosen Tetap dimulai dari skema penelitian dosen pemula, hibah bersaing atau fundamental dan hibah strategis nasional.

Setiap tahunnya, dosen tetap yang berjumlah 6 itu harus menghasilkan minimal 1 judul penelitian, atau 3 judul dengan hasil penelitian gabungan. Karena prodi TI masih memiliki 1 DT dengan JJA Asisten Ahli, maka1 DT ini di tahun 2014 hingga 2015 harus mampu menghasilkan 1 judul penelitian dengan skema dosen pemula. Hal ini dimaksudkan agar pada tahun 2016, dosen ini sudah dapat meningkatkan mutu penelitiannya dengan terjun pada skema penelitian Hibah bersaing atau fundamental.

Tidak ada jalan lain untuk dapat mengembangkan produk dalam pengembangan Lab, maka TI-UAI harus mulai mencoba untuk mendaftarkan 1 judul HKI pada tahun 2014 dan tahun 2018.

\section{KESIMPULAN}

Berdasarkan penelitian terdahulu diketahui bahwa terdapat 2 strategi yang dapat dilakukan untuk pengembangan Lab TI-UAI. Strategi pertama adalah strategi penetrasi pasar. Simulasi sistem dinamik memprediksi untuk 48 periode ke depan, bahwa skenario melaksanakan kegiatan praktikum untuk mahasiswa eksternal, training dosen dan karyawan akan lebih mendatangkan peningkatan pendapatan Lab TI jika saat ini dilaksnakan 1 minggu sekali pada setiap hari sabtu.

Hal ini terbukti dengan nilai U-Theil's yang lebih kecil dibanding skenario kedua, yaitu sebesar 0,556 . Dengan pendapatan pada akhir periode ke48 sebesar Rp.174.000.000.

Untuk strategi kedua, yaitu strategi pengembangan produk. Untuk saat ini hasil prediksi yang terbaik adalah terus konsisten produktiktif dalam menghasilkan riset, buku, HKI dan kerjasama. Hal ini dinyatakan dengan nilai U-Theil's sebesar 0,0831 . Dengan pendapatan pada akhir periode ke50 sebesar Rp.200.513.300. 
Prodi TI sebaiknya terus memotivasi Dosen Tetap agar dapat menghasilkan kinerja yang seoptimal mungkin. Selain itu, Prodi TI sebaiknya lebih jeli dalam menangkap peluang hibah atau pendanaan pengadaan peralatan Lab dari berbagai institusi, baik swasta maupun pemerintahan.

\section{DAFTAR PUSTAKA}

[1] N. Nurhasanah dan O. Deliani, Strategi Pengembangan Laboratorium Teknik Industri UAI, Jurnal Seri Sains dan Teknologi Vol 2 No 1, p. 1-15, 2013
[2] S. Wignjosoebroto, "Revitalisasi Peran dan Fungsi Laboratorium Ergonomi", 2011. [online]. Available : http://msritomo.blogspot.com/ [Accessed 19 February 2012 8:18 PM].

[3] J.W. Forrester, Industrial Dynamics, Massachusetts: The MIT Press, 1972.

[4] Muhammadi, E. Aminullah, dan B. Soesilo, Analisis Sistem Dinamis : Lingkungan Hidup, Sosial, Ekonomi, Manajemen. Jakarta: UMJ Press, 2001.

[5] N. Nurhasanah, S.N. Nurfadlilah, and $H$. Gunawarman, "Development Model of Small and Medium Scale Industry's Business Strategies for Textile Commodity in Bogor", Proceeding International Seminar: The $12^{\text {th }}$ International Seminar on QiR (Quality in Research), 2012. 


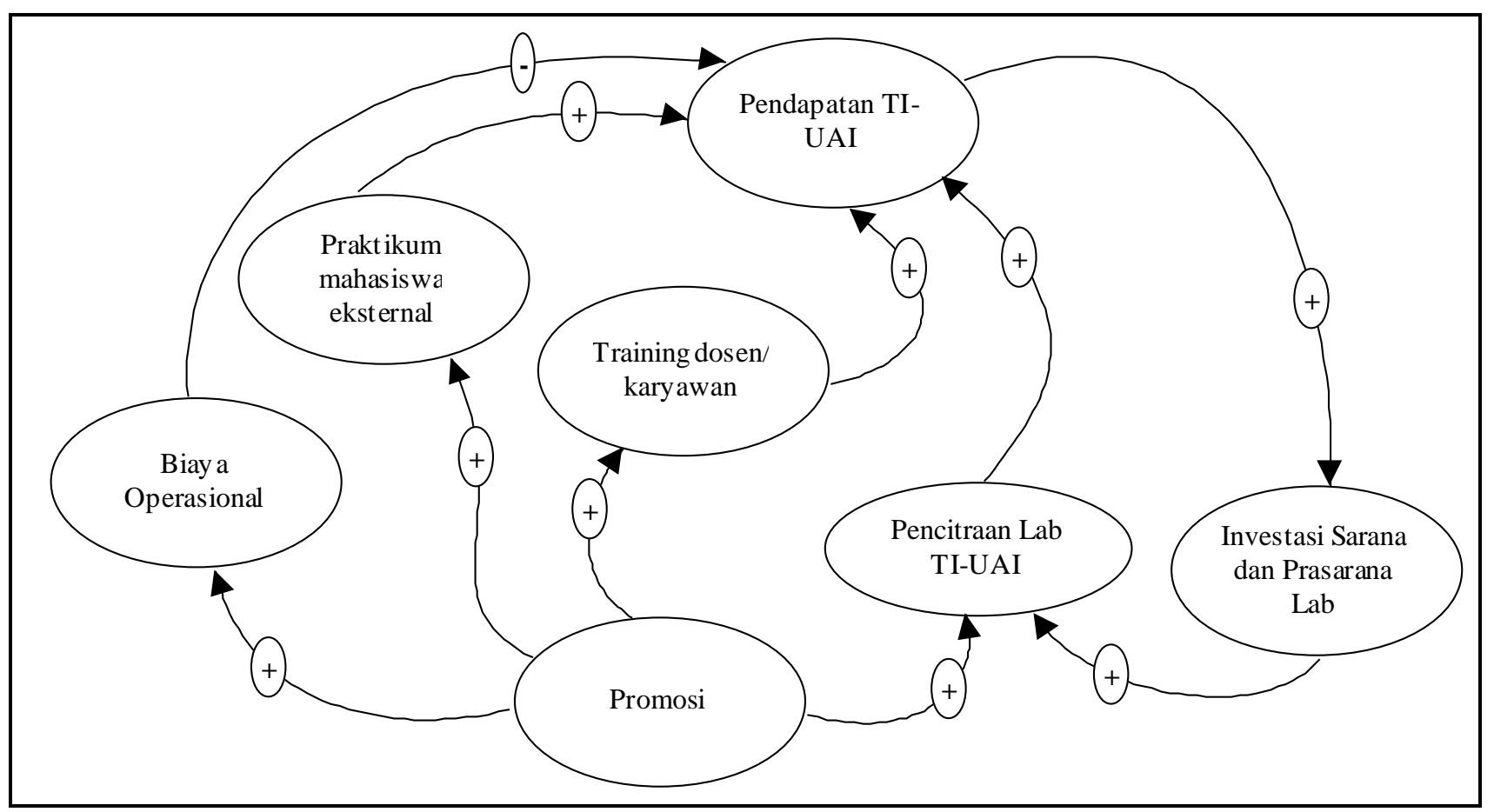

Gambar 3. CLD Sub Sistem Strategi Penetrasi Pasar

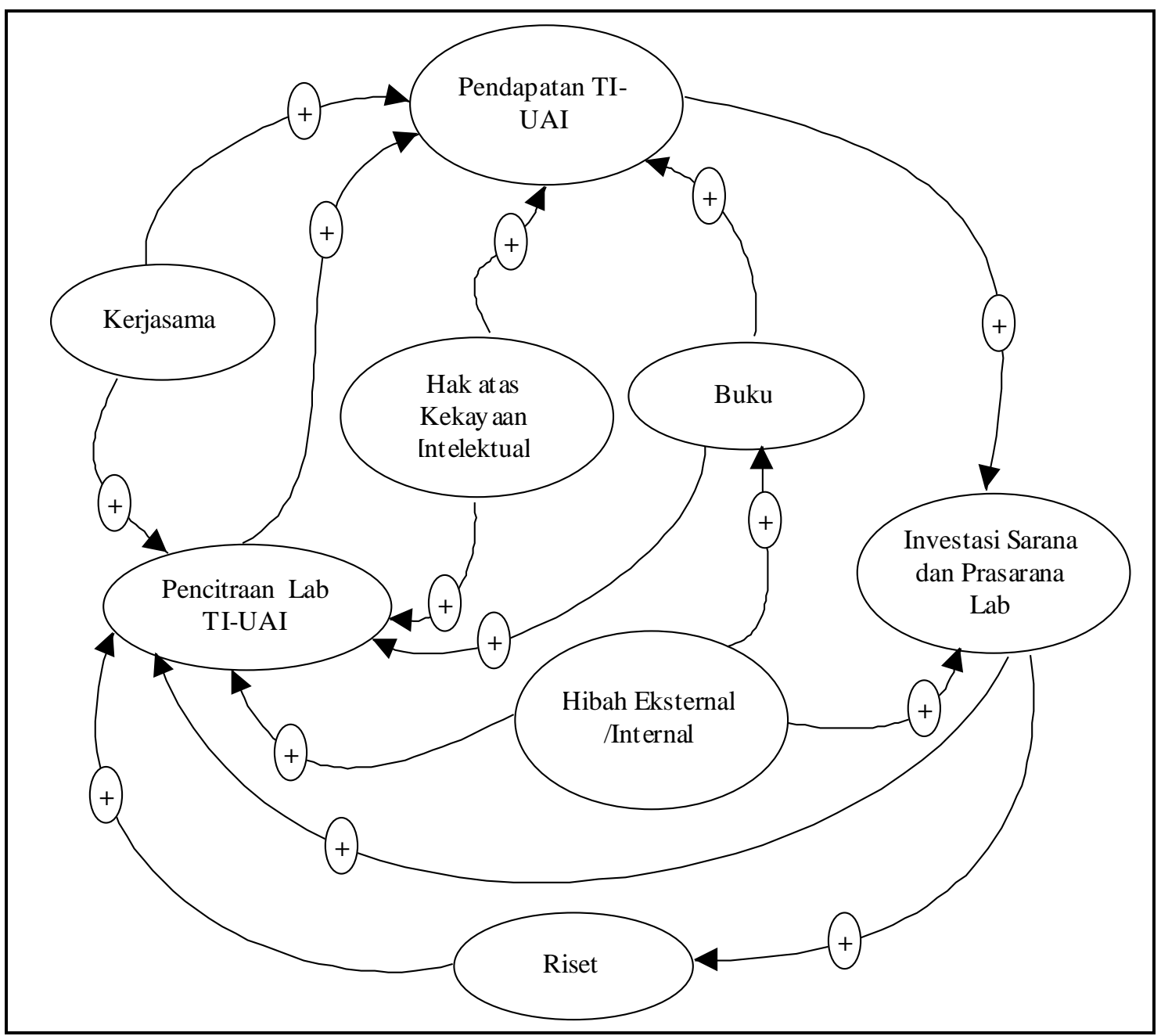

Gambar 4. CLD Sub Sistem Strategi Pengembangan Produk 
Tabel 1. Hasil Simulasi Sub Sistem Strategi Penetrasi Pasar

\begin{tabular}{|c|c|c|c|c|c|c|c|c|}
\hline Skenario & $\begin{array}{c}\text { Profit } \\
\text { Praktikum } \\
\text { Mahasiswa } \\
\text { Eksternal }\end{array}$ & $\begin{array}{l}\text { Profit } \\
\text { Training } \\
\text { Dosen }\end{array}$ & $\begin{array}{c}\text { Profit } \\
\text { Traing } \\
\text { Karyawan }\end{array}$ & Promosi & $\begin{array}{c}\text { Pengembangan } \\
\text { Sarana \& } \\
\text { Prasarana Lab }\end{array}$ & $\begin{array}{c}\text { Laju } \\
\text { Pendapatan } \\
\text { Manual }\end{array}$ & $\begin{array}{c}\text { Laju } \\
\text { Pendapatan } \\
\text { Powersim }\end{array}$ & $\begin{array}{c}\text { U- } \\
\text { Theil's }\end{array}$ \\
\hline $\begin{array}{l}\text { Pelaksanaan di } \\
\text { hari Sabtu }\end{array}$ & 56 & 160 & 160 & 11,3 & 255 & 169,750 & 174,000 & 0,0556 \\
\hline $\begin{array}{l}\text { Pelaksanaan di } \\
\text { hari Senin- } \\
\text { Jum'at }\end{array}$ & 160 & 416 & 416 & 11,3 & 255 & 185,150 & 189,400 & 0,0565 \\
\hline
\end{tabular}

Tabel 2 Hasil Simulasi Sub Sistem Strategi Pengembangan Produk

\begin{tabular}{|c|c|c|c|c|c|c|c|c|}
\hline Skenario & $\begin{array}{l}\text { Investasi } \\
\text { Riset } \\
\text { (dalam } \\
\text { juta Rp.) }\end{array}$ & $\begin{array}{c}\text { Investasi } \\
\text { Buku }\end{array}$ & $\begin{array}{c}\text { Investasi } \\
\text { Kerjasama } \\
\text { (dalam juta } \\
\text { Rp.) }\end{array}$ & $\begin{array}{c}\text { Investasi } \\
\text { HKI } \\
\text { (dalam } \\
\text { juta Rp.) }\end{array}$ & $\begin{array}{c}\text { Pengembangan } \\
\text { Sarana \& } \\
\text { Prasarana Lab } \\
\text { (dalam juta Rp.) }\end{array}$ & $\begin{array}{c}\text { Laju } \\
\text { Pendapatan } \\
\text { Manual } \\
\text { (dalam } \\
\text { juta Rp.) }\end{array}$ & $\begin{array}{c}\text { Laju } \\
\text { Pendapatan } \\
\text { Powersim } \\
\text { (dalam } \\
\text { juta Rp.) }\end{array}$ & $\begin{array}{c}\text { U- } \\
\text { Theil's }\end{array}$ \\
\hline $\begin{array}{l}\text { entasi } \\
\text { stasi } 10 \%\end{array}$ & 143 & 13.500 & 170 & 0,520 & 690 & 201,253 & 200,513 & 0,0831 \\
\hline $\begin{array}{l}\text { entasi } \\
\text { stasi } 20 \%\end{array}$ & 286 & 27.000 & 340 & 1,040 & 690 & 550,520 & 543,527 & 0,1490 \\
\hline
\end{tabular}




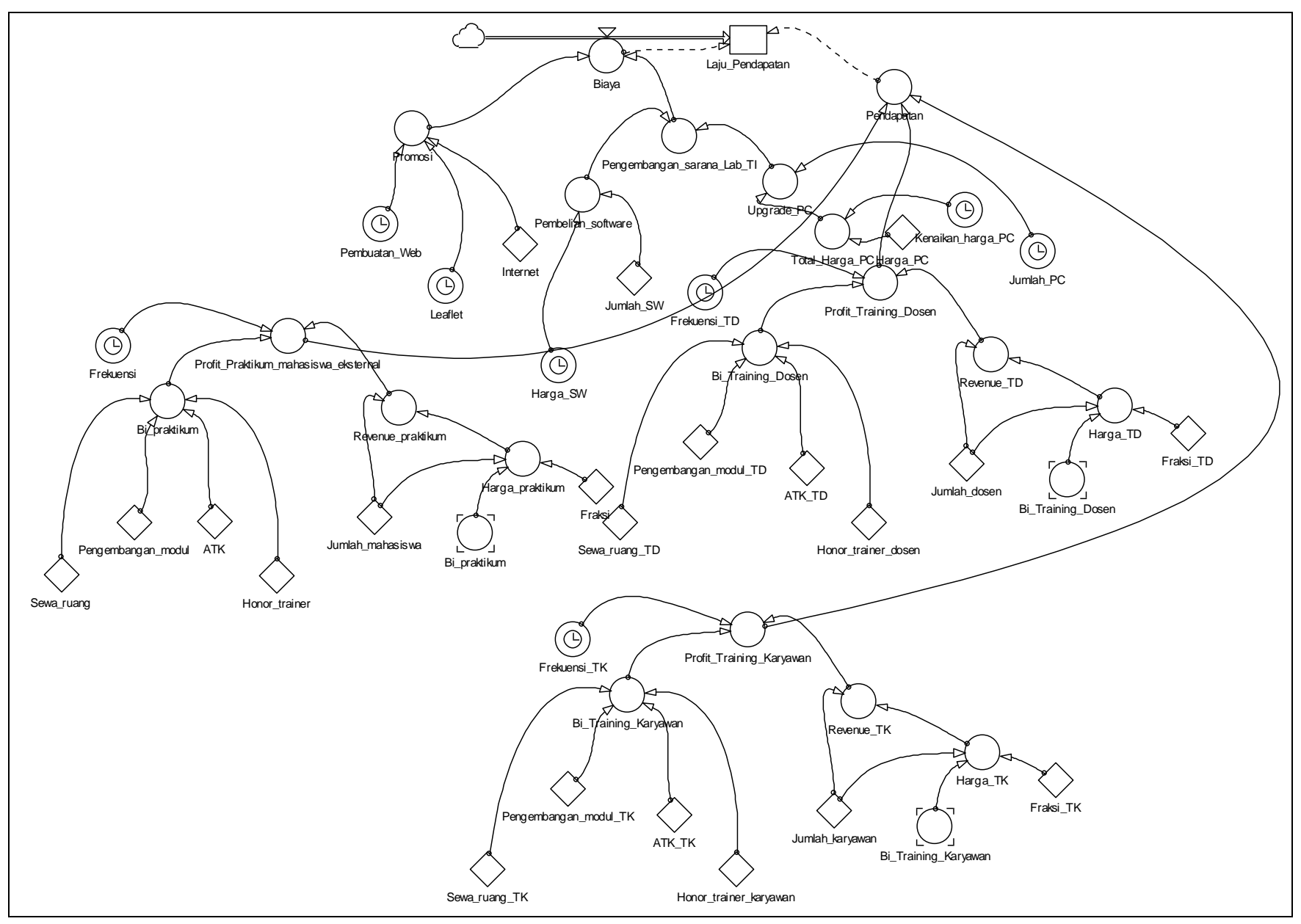

Gambar 5. SFD Strategi Penetrasi Pasar 


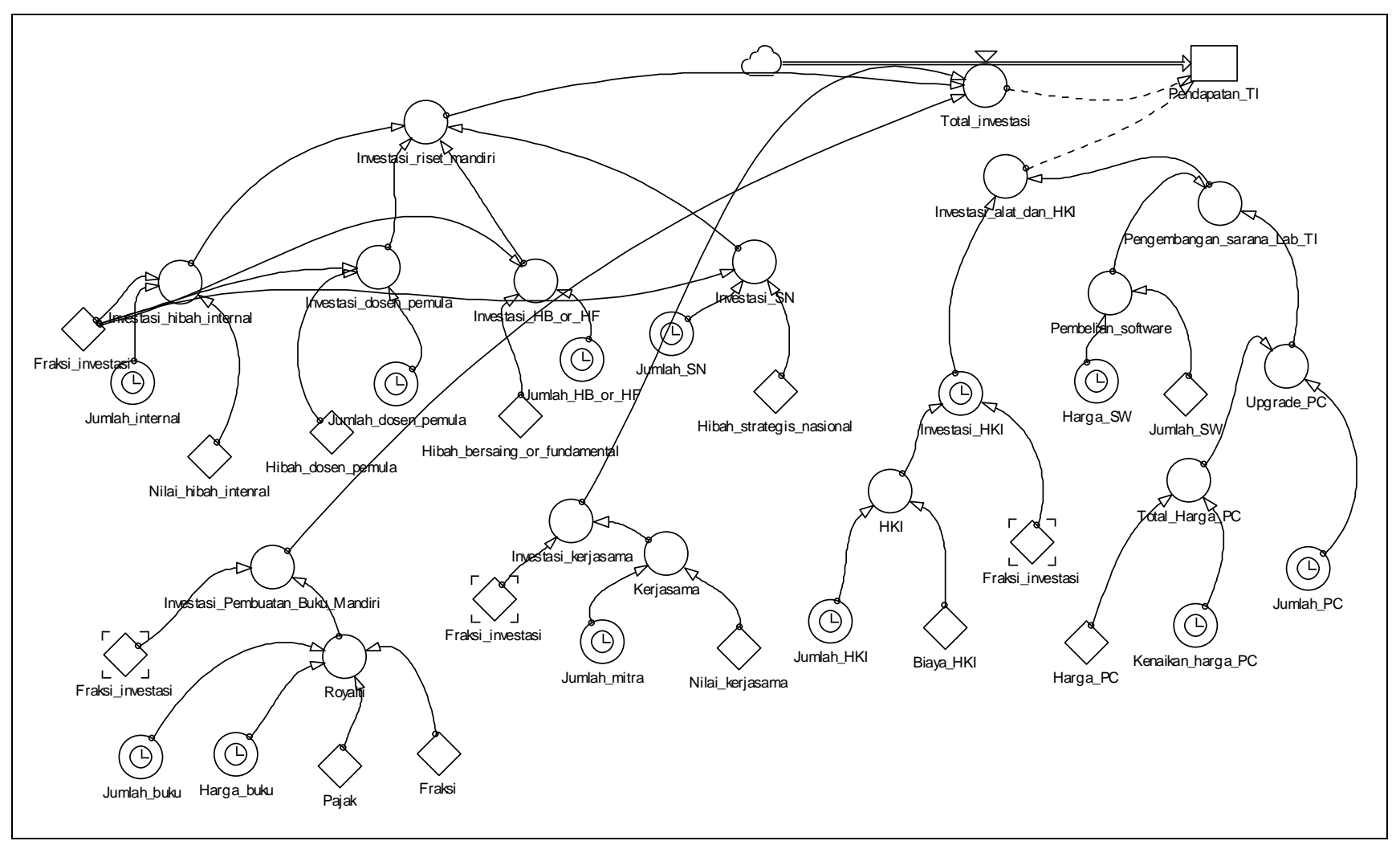

Gambar 6. SFD Strategi Pengembangan Produk 

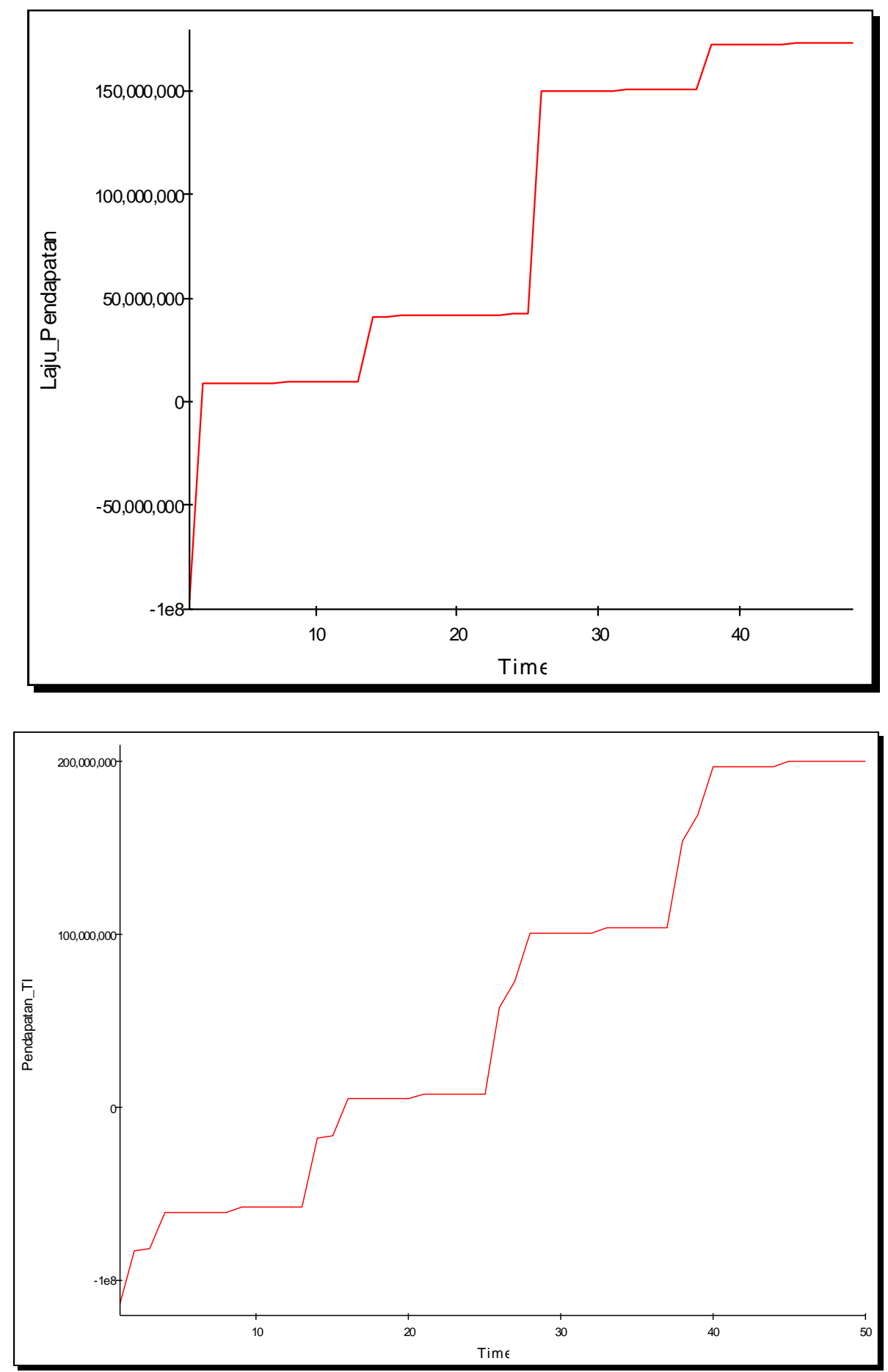

Gambar 7. Grafik Pendapatan Prodi untuk Strategi Penetrasi Pasar dan Strategi Pengembangan Produk 